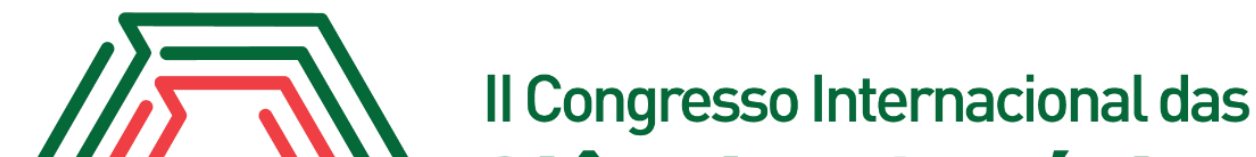 Ciências Agrárias COINTER - PDVAgro 2017
}

\section{DESENVOLVIMENTO DOS ESTÔMAGOS DE BEZERROS ALEITADOS COM LEITE EM PÓ E SORO DE QUEIJO EM PÓ RECONSTITUÍDOS}

\author{
Apresentação: Pôster
}

Maria Vivianne Freitas Gomes de Miranda ${ }^{1}$; Tiago da Silva Teófilo² ${ }^{2}$ Ana Paula Pinheiro de Assis $^{3}$; José Domingues Fontenele Neto ${ }^{4}$; Patrícia de Oliveira Lima ${ }^{5}$

\section{Introdução}

Os ruminantes, ao nascerem, apresentam o trato gastrointestinal parcialmente estéril com préestômagos pequenos e não funcionais, sendo considerados não ruminantes. $\mathrm{O}$ rápido desenvolvimento desses compartimentos está associado ao tipo de manejo alimentar adotado na fase de cria (Khan et al., 2016).

A capacidade de todos os compartimentos estomacais se modificam de maneira distinta com o avanço da idade dos bezerros, com uma aceleração do crescimento ruminal e uma retração do crescimento abomasal. Ao nascer, a atividade digestiva no bezerro é exercida pelo abomaso. Nesses animais o retículo-rúmen representa apenas 30\% do total dos quatro compartimentos. As maiores mudanças em termos de desenvolvimento vão ocorrer neste órgão, o qual será colonizado por diferentes tipos de microrganismos e terá sua musculatura e parede interna desenvolvidas, como também enzimas funcionais na parede do rúmen (Carvalho et al. 2003).

Em bovinos jovens, recebendo alimento sólido até a nona semana de vida, estes já podem apresentar colonização de microrganismos anaeróbios ou anaeróbios facultativos em elevadas concentrações no interior do rúmen (Júnior et al. 2016), nessa idade o animal já está em processo de transição. A dieta, a qualidade e a frequência da alimentação fornecida são fatores importantes para o bom desenvolvimento dos estômagos (Rasmussen et al., 2006).

\footnotetext{
${ }^{1}$ Doutora em Ciência Animal, Universidade Federal Rural do Semiárido, mviviannefreitas@hotmail.com

${ }^{2}$ Doutorando em Ciência Animal, Universidade Federal Rural do Semiárido, tiago.teofilo@ufersa.edu.br

${ }^{3}$ Doutora em Ciência Animal, Universidade Federal Rural do Semiárido, pinheiropaula87@hotmail.com

${ }^{4}$ Docente na Universidade Federal Rural do Semiárido, pattlima@ufersa.edu.br

${ }^{5}$ Docente na Universidade Federal Rural do Semiárido, fontenele@ufersa.edu.br
} 
Objetivou-se com o presente trabalho avaliar a utilização do soro de queijo em pó associado ao leite em pó como substituto do leite integral no aleitamento de bezerros até os 60 dias de vida sobre

o desenvolvimento dos pré-estômagos. a influência da utilização do soro de queijo in natura associado ao leite em pó nas células produtoras de quimosina (renina) e pepsina no abomaso de bezerros.

\section{Fundamentação Teórica}

A fase de cria de bezerros em aleitamento artificial representa uma das etapas mais relevantes na produção leiteira e pode comprometer a vida futura do rebanho (Júnior et. al., 2016). A utilização de dietas líquidas alternativas vem sendo estudada visando à substituição parcial ou total do leite na dieta. O uso desses produtos permite aos produtores a venda de maior volume de leite, com consequente aumento da disponibilidade para a indústria e para a alimentação humana (Fontes et. al., 2006). Entretanto, a utilização de produtos desta natureza demonstra, em muitos casos, disparidades no desempenho dos animais, principalmente associados com alimentos de menor aproveitamento, gerando diminuição no ganho de peso e elevação do gasto com medicamentos, quando comparados ao leite integral.

Nesse contexto, a busca por alternativas que possam reduzir os custos com o fornecimento de leite aos animais e garantir maior retorno econômico para os produtores são fatores importantes. A utilização de substitutos lácteos no aleitamento de animais devido ao seu baixo custo tem motivado pesquisas. Sucedâneos como o soro de queijo e o leite em pó podem ser utilizados como substâncias alternativas ao leite integral, pois são produtos de descarte nas indústrias de queijo e nas fábricas de produção de leite em pó, que são vendidos a preços baixos, e possuem características similares as do leite integral.

\section{Metodologia}

Foram utilizados 24 bezerros machos mestiços com idade $5 \pm 3$ dias e peso médio inicial de $35 \mathrm{~kg}$. Os animais foram distribuídos em delineamento inteiramente casualizado com 4 (quatro) tratamentos e 6 (seis) repetições: LI: leite integral (controle); LP: leite em pó; LPS1:80\% leite em pó $+20 \%$ de soro de queijo em pó; LPS2: $60 \%$ leite em pó + $40 \%$ de soro de queijo em pó. O leite em pó e o soro de queijo em pó utilizados nesse experimento, foram obtidos de refugo de uma indústria de laticínios da região. 
Os bezerros receberam colostro integral até o terceiro dia de vida e posteriormente foram aleitados com leite integral na quantidade de quatro litros, fornecido duas vezes ao dia (manhã e tarde) até o décimo dia. Os animais foram mantidos no sistema de confinamento em baias individuais cobertas com sombrite, onde tinham acesso ao concentrado farelado, feno de Tifton (Cynodon sp.) e água ad libitum, desde o nascimento até o desaleitamento.

Aos 60 dias de idade, antes de serem abatidos, os bezerros foram pesados e submetidos a um jejum de aproximadamente 16 horas (período noturno), tendo acesso à água. Na manhã seguinte, foram pesados novamente e levados ao abatedouro sob fiscalização do Serviço de Inspeção Municipal. Os órgãos cavitários foram pesados com conteúdo e logo em seguida, esvaziados, lavados, escorridos e novamente pesados, registrando-se, portanto, os pesos cheios e vazios, respectivamente. O peso corporal vazio (PCVZ), utilizado para as comparações percentuais, foi obtido diretamente pelo somatório dos pesos de patas, cabeça, pele, sangue, órgãos, vísceras vazias, gordura interna e carcaça.

Os dados foram submetidos à análise de variância e teste de comparação de médias. Os efeitos dos diferentes tratamentos sobre cada variável foram comparados por meio do teste de Tukey, ao nível de 5\% de probabilidade com o auxílio computacional do programa IBM (IBM Statistics 20).

\section{Resultados e Discussões}

As médias obtidas para pesos absolutos e relativos dos compartimentos gástricos, em função do peso do corpo vazio não apresentaram diferenças significativas $(\mathrm{P}>0,05)$, assim como a participação percentual dos compartimentos gástricos, o peso total dos estômagos vazios e o conteúdo dos 4 compartimentos gástricos $(\mathrm{P}>0,05)$.

Azevedo et al. (2013) relataram que a proporção do rúmen-retículo, omaso e abomaso de bezerros lactantes foram de 66\%, $15 \%$ e $19 \%$ respectivamente. Silper et al (2012), estudando diferenças na proporção de cada estômago aos 30 e 60 dias de vida de bezerros, verificaram que o ruminorretículo correspondeu a maior parte do trato gastrointestinal nas duas idades. Resultados semelhantes foram encontrados neste experimento, onde o rúmen supera em peso e proporção o abomaso, caracterizando esses bezerros como ruminantes funcionais. Quando nascem os bezerros possuem o retículo-rúmen pouco desenvolvido, representando em torno de $30 \%$ do total dos quatro compartimentos, para que haja um rápido desenvolvimento desse órgão a dieta é o fator principal, a aceleração do desenvolvimento do retículo-rúmen se dá à medida que o animal consome alimentos 
sólidos (Costa et al., 2008).

Tabela 1 - Peso absoluto do estômago vazio $(\mathrm{kg})$, relativo em função do peso do corpo vazio (\%PCVZ), relativo em função do peso do estômago total (\%PE) e conteúdo dos compartimentos gástricos (kg) de bezerros submetidos a dietas contendo soro de queijo em pó associado ao leite em pó. Fonte: Própria

\begin{tabular}{|c|c|c|c|c|c|c|}
\hline \multirow[b]{2}{*}{ Variável } & \multicolumn{3}{|c|}{ Dieta Líquida } & \multirow[b]{2}{*}{ LPS2 } & \multirow[b]{2}{*}{$\mathrm{P}$} & \multirow[b]{2}{*}{$\mathrm{CV}$} \\
\hline & LI & LP & LPS1 & & & \\
\hline \multicolumn{7}{|c|}{ |-----------------------------------kg--------------------------------- } \\
\hline Estômago total & $1,41^{\mathrm{a}}$ & $1,41^{\mathrm{a}}$ & $1,58^{\mathrm{a}}$ & $1,57^{\mathrm{a}}$ & 089 & 2645 \\
\hline Rúmen-retículo & $0,86^{\mathrm{a}}$ & $0,94^{\mathrm{a}}$ & $1,04^{\mathrm{a}}$ & $1,00^{\mathrm{a}}$ & 076 & 2619 \\
\hline Omaso & $0,16^{\mathrm{a}}$ & $0,17^{\mathrm{a}}$ & $0,20^{\mathrm{a}}$ & $0,21^{\mathrm{a}}$ & 087 & 42,16 \\
\hline Abomaso & $0,38^{\mathrm{a}}$ & $0,30^{\mathrm{a}}$ & $0,35^{\mathrm{a}}$ & $0,36^{\mathrm{a}}$ & 0.74 & 30.28 \\
\hline \multicolumn{7}{|c|}{--------------------------------\%PCVZ---------------------------- } \\
\hline & & & $221 \mathrm{a}$ & & & \\
\hline Estômago total & $2,82^{a}$ & $3,19^{a}$ & $3,31^{\text {a }}$ & $3,43^{\mathrm{a}}$ & 0,46 & 18,94 \\
\hline Rúmen-retículo & $1,73^{\mathrm{a}}$ & $2,09^{\mathrm{a}}$ & $2,18^{\mathrm{a}}$ & $2,20^{\mathrm{a}}$ & 0,17 & 18,76 \\
\hline Omaso & $0,32^{\mathrm{a}}$ & $0,38^{\mathrm{a}}$ & $0,41^{\mathrm{a}}$ & $0,44^{\mathrm{a}}$ & 0,61 & 34,20 \\
\hline Abomaso & $0,76^{\mathrm{a}}$ & $0,71^{\mathrm{a}}$ & $0,72^{\mathrm{a}}$ & $0,80^{\mathrm{a}}$ & 0,10 & 28,76 \\
\hline \multicolumn{7}{|c|}{----------------------------------\%PE------------------------------- } \\
\hline Rúmen-retículo & $61,19^{\mathrm{a}}$ & $66,77^{\mathrm{a}}$ & $66,01^{\mathrm{a}}$ & $64,26^{\mathrm{a}}$ & 0,43 & 8,75 \\
\hline Omaso & $11,73^{\mathrm{a}}$ & $11,80^{\mathrm{a}}$ & $12,51^{\mathrm{a}}$ & $11,94^{\mathrm{a}}$ & 0,99 & 24,54 \\
\hline Abomaso & $27,08^{\mathrm{a}}$ & $21,35^{\mathrm{a}}$ & $21,48^{\mathrm{a}}$ & $23,80^{\mathrm{a}}$ & 0,26 & 21,75 \\
\hline \multicolumn{7}{|c|}{ - } \\
\hline Rúmen-retículo & $2,67^{\mathrm{a}}$ & $3,73^{\mathrm{a}}$ & $4,39^{\mathrm{a}}$ & $4,37^{\mathrm{a}}$ & 0,39 & 47,28 \\
\hline Omaso & $0,07^{\mathrm{a}}$ & $0,10^{\mathrm{a}}$ & $0,10^{\mathrm{a}}$ & $0,10^{\mathrm{a}}$ & 0,86 & 69,71 \\
\hline Abomaso & $0,58^{\mathrm{a}}$ & $0,44^{\mathrm{a}}$ & $0,56^{\mathrm{a}}$ & $0,66^{\mathrm{a}}$ & 0,83 & 54,00 \\
\hline
\end{tabular}

Médias com letras diferentes nas linhas são significativas $(\mathrm{P}<0,05)$ pelo teste de Tukey;

LI: Leite integral; LP: leite em pó; LPS1: $80 \%$ leite em pó + 20\% de soro de queijo em pó; LPS2: $60 \%$ leite em pó + $40 \%$ de soro de queijo em pó.

Segundo Mancio et al. (2005), o tamanho do rúmen está relacionado à sua capacidade funcional, portanto, os elevados pesos deste órgão podem demonstrar uma transformação numa 
estrutura funcional. O maior desenvolvimento do rúmen ocorre devido à presença de alimentos sólidos, proporcionando maior motilidade ruminal, desenvolvimento epitelial, muscular, além da produção de ácidos graxos voláteis (Anderson et al.,1987).

Os bezerros apresentaram um desenvolvimento normal dos estômagos, já que não foram apresentadas diferenças estatisticamente significativas em relação aos pesos absolutos e percentuais, tanto em relação ao peso do corpo vazio quanto ao peso do estômago, nas dietas testadas.

\section{Conclusões}

O soro de queijo associado ao leite em pó não afetou o desenvolvimento anatômico e fisiologico dos estômagos dos bezerros, caracterizando-os como ruminantes funcionais.

\section{Referências}

ANDERSON, K.L. et al. Ruminal metabolic development in calves weaned conventionally or early. J. Dairy Sci., Savoy, v.70, n. 5, p.1000-1005, 1987.

AZEVEDO, Rafael A. et al. Desenvolvimento do trato digestivo de bezerros leiteiros criados em sistema de aleitamento fracionado. Pesquisa Veterinária Brasileira, v. 33, n. 7, p. 931-936, 2013.

CARVALHO, P.A.; SANCHEZ, L.M.B.; VIÉGAS, J. et al. Componentes do peso vivo e órgãos viscerais de bezerros machos de origem leiteira ao nascimento, 50 e 110 dias de vida. Revista Brasileira de Zootecnia,v.32, n.6, p.1469-1475, 2003.

COSTA, S. F. et al. Alterações morfológicas induzidas por butirato, propionato e lactato sobre a mucosa ruminal e a epiderme de bezerros. Arq. Bras. Med. Vet. Zootec, p. 1-9, 2008.

FONTES, F. A.P.V.; COELHO, S.G.; LANA, A.M.Q., COSTA, T.C.; CARVAlHO, A.U. Desempenho de bezerros alimentados com dietas liquidas a base de leite integral ou soro de leite. Arquivo Brasileiro de Medicina Veterinária e Zootecnia, v. 58, n.2, p.212-219, 2006.

JÚNIOR, V. F. G.; AZEVEDO, R. A.; ORNELAS, L. T. C.; OLIVEIRA, N. J. F.; GERASEEV, L. C.; DUARTE E. R.; Caracterização físico-química e microbiológica do fluido ruminal e do conteúdo gastrointestinal de bezerros holandeses em aleitamento artificial convencional ou fracionado. Acta Veterinaria Brasilica, v.10, n.4, p.305-313, 2016.

KHAN, M. A. et al. Invited review: Transitioning from milk to solid feed in dairy heifers. Journal of Dairy Science, v. 99, n. 2, p. 885-902, 2016.

KAMRA, D. N. Rumen microbial ecosystem. Current Science, v. 89, p. :124-135, 2005.

RASMUSSEN, M.A., et al. Rumen contents as a reservoir of enterohemorrhagic Escherichia coli. FEMS Microbial Letter, v.114, p. 79-84, 2006. 
SILPER B.F. 2012. Efeitos de três estratégias de aleitamento sobre ganho de peso, desenvolvimento ruminal e perfil metabólico e hormonal de bezerros Holandeses. Dissertação de Mestrado em Zootecnia, Escola de Veterinária, Universidade Federal de Minas Gerais, Belo Horizonte, MG. 96p.

MANCIO, A. B. Desempenho de produtivo de cabritos alimentados com diferentes dietas liquidas associados com um promotor de crescimento. Revista Brasileira de Zootecnia, V. 34, p. 1305 1313, 2005. 